\title{
Effect of Vitamin on Accumulation of PHB by Zobellella Species under Submerged Fermentation Process
}

\author{
S. Maity ${ }^{1}$, S. Das ${ }^{2}$ and D.P. Samantaray ${ }^{1} *$ \\ ${ }^{1}$ Department of Microbiology, CBSH, OUAT, Bhubaneswar-3, Odisha-751003, India \\ ${ }^{2}$ Department of Life Science, LEnME, NIT, Rourkela, Odisha - 769008, India \\ *Corresponding author
}

\begin{tabular}{|c|c|}
\hline & A B S T R A C T \\
\hline $\begin{array}{l}\text { Ke y w o r d s } \\
\text { Eco-pollution, } \\
\text { PHB, Zobellella, } \\
\text { FTIR, } \\
\text { Vitamins. }\end{array}$ & \multirow{3}{*}{$\begin{array}{l}\text { In the current context of eco-pollution, the substitute of conventional plastics with } \\
\text { bioplastics is a big confront. On account of that, a non-growth associated PHB production } \\
\text { study was conducted using Zobellella species under submerged fermentation process. As a } \\
\text { result, Zobellella species showed the ability to accumulate } 2.2 \mathrm{~g} / \mathrm{L} \text { of PHB at } \mathrm{pH} 8 \text {, } 0 \text {, } \\
\text { temperature } 37^{\circ} \mathrm{C} \text {, salt concentration } 2 \% \text { in modified growth medium containing vitamins. } \\
\text { Then, primary structural characterization of extracted polymer was conducted by FTIR } \\
\text { analysis. The high intense peak was obtained at } 1720.50 \mathrm{~cm}^{-1} \text { corresponding to ester } \\
\text { carbonyl }(\mathrm{C}=\mathrm{O}) \text { stretching vibration of PHB. This finding will be paved the way of } \\
\text { researchers during selection of suitable vitamins containing inexpensive carbon sources for } \\
\text { cost effective PHB production. Thus, extensive research is highly indispensible for } \\
\text { bioconversion of vitamin containing raw materials to PHB. }\end{array}$} \\
\hline Article Info & \\
\hline $\begin{array}{l}\text { Accepted: } \\
\text { 22 January } 2017 \\
\text { Available Online: } \\
\text { 10 February } 2017\end{array}$ & \\
\hline
\end{tabular}

\section{Introduction}

In response to risk associated with petrochemical based plastic waste and its effect on the environment, there has been considerable interest on the development and production of an alternative, biodegradable plastic. In the current context of ecopollution, the substitute of conventional plastics with bioplastics is a big confront. Moreover, their development became indispensable due to the depletion of fossil fuel reserves, high oil prices and increased greenhouse gas emissions. Reports also suggested that burning of bioplastics producing methane, which can be further used as source of energy (Versa and Savita, 2011). Polyhydroxyalkanoates (PHAs) are group of most common biopolymers or bioplastics found in Gram positive (Kalaivani and Sukumaran 2015; Mohapatra et al., 2016 and Chaudhry et al., 2010) and Gram negative bacteria (Ibrahim and Steinbuchel, 2009; Tortajada et al., 2013 and Poli et al., 2011). PHAs include poly- $(R)$-3-hydroxybutyrate (PHB), a copolymer (PHBV) of $(R)-3$ hydroxybutyrate (3HB) and $(R)-3$ hydroxyvalerate $(3 \mathrm{HV})$ and a copolymer (PHBHHx) of 3HB and (R)-3hydroxyhexanoate $(3 \mathrm{HHx})$ are produced by various microbes (Xiao and Jiao, 2011; Mohapatra et al., 2014).

These PHAs has a wide range of applications such as plastics materials, medical implants, drug delivery carriers, printing and 
photographic materials, nutritional supplements, drugs and fine chemicals (Chen, 2009).

Wide-spread substitution of conventional plastics has been limited due to their high production costs, which hold back its successful commercialization (Waltz, 2008). Thus, additional efforts are needed for making this process economically feasible by analysing inherent mechanism of PHAs accumulation process and improving its productivity. Therefore, exploitation of improved cultivation medium, culture conditions, inexpensive carbon sources and genetically modified microbes can be reduced cost of PHB production (Castilho et al., 2009; Khanna and Srivastava, 2005). Thus, the objective of study is to determine the effect of different vitamins on PHB production using high yielding bacterial isolates. This will be paved the way of lead researchers regarding bioconversion of vitamin containing inexpensive carbon sources for cost effective PHB production.

\section{Materials and Methods}

\section{Culture collection}

In our preceding work, the Gram-negative Zobellella strain was found to produce $2.2 \mathrm{~g} / \mathrm{L}$ PHB from $3.0 \mathrm{~g}$ biomass (CDW) in modified growth medium under optimized growth condition. The preserved $\left(-20^{\circ} \mathrm{C}\right)$ bacterial isolate was revived and induced synthesis of PHB granule in their cytosol using modified growth medium (Mohapatra et al., 2015). Then, occurrence of PHB granule in the cytosol was detected by Sudan black (Mohapatra et al., 2015) and Nile red staining (Spiekerman et al., 1999). All the chemicals and culture media used in the study are procured from Merck Millipore and Hi-media Laboratories Private Limited.

\section{PHB production under submerged fermentation}

One-stage batch cultivation in shake flasks method was conducted for accumulation of PHB granule in the bacterial cell. The Zobellella strain was subjected to PHB production under optimized growth conditions. Briefly, 1L of PHB production medium containing Glutamic acid $3.8 \mathrm{~g} / \mathrm{L}$; Malic acid $2.7 \mathrm{~g} / \mathrm{L} ; \mathrm{Na}_{2} \mathrm{HPO}_{4} 1.5 \mathrm{~g} / \mathrm{L} ; \mathrm{KH}_{2} \mathrm{PO}_{4}$ $2.5 \mathrm{~g} / \mathrm{L} ; \mathrm{K}_{2} \mathrm{HPO}_{4} 2.5 \mathrm{~g} / \mathrm{L} ; \mathrm{NaCl} 20 \mathrm{~g} / \mathrm{L} ; \mathrm{CaCl}_{2}$, $2 \mathrm{H}_{2} \mathrm{O} 0.2 \mathrm{~g} / \mathrm{L} ; \mathrm{MgSo}_{4} 0.8 \mathrm{~g} / \mathrm{L} ; \mathrm{MnSo}_{4} 0.001$ $\mathrm{g} / \mathrm{L} ; \quad 7 \mathrm{H}_{2} \mathrm{O} \quad 0.8 \mathrm{~g} / \mathrm{L} ; \quad\left(\mathrm{NH}_{4}\right)_{2} \mathrm{SO}_{4} 3.08 \mathrm{~g} / \mathrm{L}$; Glucose $20 \mathrm{~g} / \mathrm{L}$ was prepared with $\mathrm{pH} 8.0$ and then supplemented with filter $(0.45 \mu \mathrm{m})$ sterilized vitamins solution (Biotin, Thiamine, Niacin, Riboflavin, Folic acid and Patnothenic acid; each $1 \mathrm{mg} / \mathrm{L}$ ) individually and in different combination. Subsequently, submerged fermentation process was carried out with $15 \%$ of inoculum (overnight culture containing $1.5 \times 10^{8}$ cells $/ \mathrm{ml}$ ) at temperature $37^{\circ} \mathrm{C}$ for $72 \mathrm{~h}$ with an agitation rate of 150 rpm.

\section{Extraction and quantitative analysis of PHB}

PHB extraction was carried out by sodium hypochlorite digestion and multi-solvent extraction method (Mohapatra et al., 2015). Then, bacterial cells were harvested by centrifugation at $10,000 \mathrm{~g}$ for $15 \mathrm{~min}$, dried at $50^{\circ} \mathrm{C}$ to obtain dry cell mass (DCM) and treated with sodium hypochlorite to digest the non PHAs materials (NPM). The mixture was then centrifuged and subsequently washed twice with acetone, methanol and diethyl ether $(1: 1: 1)$ to remove sodium hypochlorite and debris. Finally, the PHB were dissolved in boiling chloroform to remove all the remaining organic solvents present with PHB pellets and subsequent evaporation by air drying to yield dried form of extracted PHB. 
PHB production was also quantified using standard formula.

\section{Characterization of PHB by FTIR Analysis}

The functional groups present in the PHB were analyzed by FTIR spectroscopy. PHB sample was mixed with $2 \% \mathrm{KBr}$ and compressed into translucent sample discs and fixed in the FTIR spectrometer (Perkin-Elmer RX I). Scans were accomplished at spectral range, 4000-400 $\mathrm{cm}^{-1}$; window material, CsI; 16 scans and resolution $4 \mathrm{~cm}^{-1}$. The detection was conducted with a temperature stabilized, coated FRDTGS detector (Dash et al., 2014).

\section{Results and Discussion}

Although wide arrays of bacterial species accumulate PHAs, however the major limitations in the production of PHAs are selection of inexpensive materials and its composition, producer microbes, bioprocess condition, fermentation process and high cost downstream processing. Among all selection of inexpensive material and its composition is the predominant factor affecting PHAs production bioprocess technology. As regards $50 \%$ of the production costs of PHAs is depend upon cost of carbon sources and vitamins supplemented in the production medium (Gomma, 2014). In this small piece of research an attempt has been made to study the effect of different vitamin such as biotin, thiamin, niacin, riboflavin, folic acid and patnothenic acid on PHAs accumulation by bacterial isolate.

\section{PHAs production}

From the result (Figure 1), it was found that biomass production by the bacterial isolate ranged between $1.20-4.20 \mathrm{~g} / \mathrm{L}$ in presence of different vitamins. The biomass production was increased with supplementation of thiamin and decreased with folic acid. Thus, thiamine has higher effect on cellular growth than other vitamin supplemented in the medium. Consequently, PHAs production was found to be $0.062-1.835 \mathrm{~g} / \mathrm{L}$ and was higher in presence of thiamin and lower with folic acid. The PHAs production was $1.835 \mathrm{~g} / \mathrm{L}$ and $1.790 \mathrm{~g} / \mathrm{L}$ in presence of thiamin and biotin respectively. Notably, no significant difference of PHAs production was observed between thiamin and biotin as source of vitamin. However, percentage of PHAs production was $65.42 \%$ and $42.93 \%$ on supplementation of biotin and thiamin respectively. Hence biotin has a major role on PHAs yield, which is not parallel to biomass production in case of Zobellella species. Similarly, different combinatorial effect of vitamin on PHAs production results (Figure 2) indicated that, the biomass and PHAs yield was varied between 2.601-3.847 $\mathrm{g} / \mathrm{L}$ and $1.401-2.085 \mathrm{~g} / \mathrm{L}$ respectively. The biomass and PHAs production was increased with supplementation of biotin and thiamin combination and decreased with riboflavin and folic acid. However, higher percentage $(68.14 \%)$ of PHAs production was obtained on supplementation of multi-vitamin such as biotin and riboflavin in the production medium. From the above data, it is concluded that biotin has a noteworthy role on PHAs production nevertheless after supplementation of biotin, thiamine, niacin, riboflavin, folic acid and patnothenic acid production was increased to $2.2 \mathrm{~g} / \mathrm{L}$ by Zobellella species.

No comprehensible evident is available in the public domain regarding increase in PHAs production by Zobellella species on supplementation of vitamin. In addition, vitamins including thiamin, riboflavin and biotin are essential growth factors for different bacterial isolates (Du et al., 2011; Preciado et al., 2015). Thus, vitamin and amino acids can be supplemented for efficient PHAs production (Varsha and Savitha, 2011). In contrast to our observation, biotin is also 
able to switch the carbon flux of acetyl-CoA towards biosynthesis of PHB by Corynebacterium glutamicum thereby increases production (Jin et al., 2009). However, vitamin was no effect on PHB production by Pseudomonas pseudomallei and Rhodobacter sphaeroides $14 \mathrm{~F}$
(Chowdhury et al., 2005; Sangkharak and Prasertsan 2008). In our observation the PHAs production was increased with supplementation of vitamins such as biotin, thiamin and riboflavin, which suggesting selection of vitamin containing raw material for cost effective production.

Fig.1 Effect of vitamins on cell biomass and PHAs production

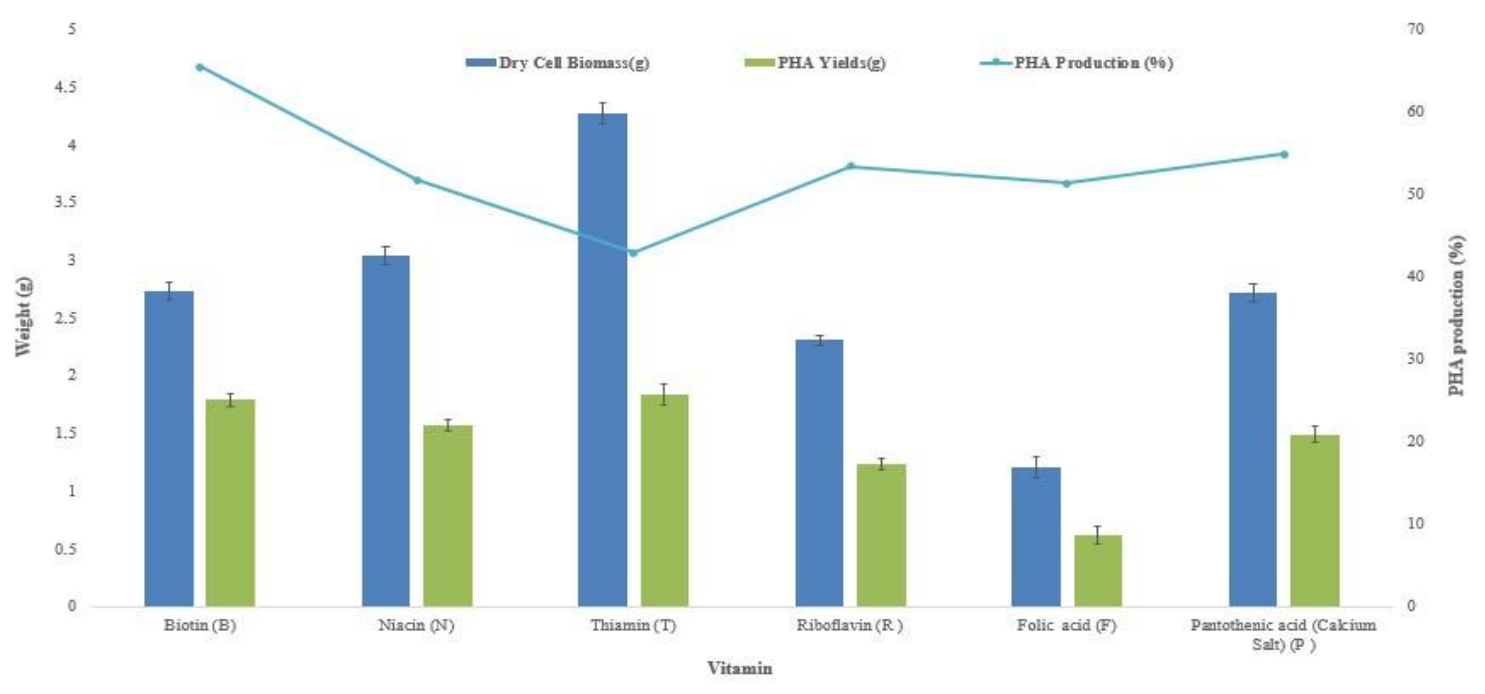

Fig.2 Effect of vitamins (combination) on cell biomass and PHAs production

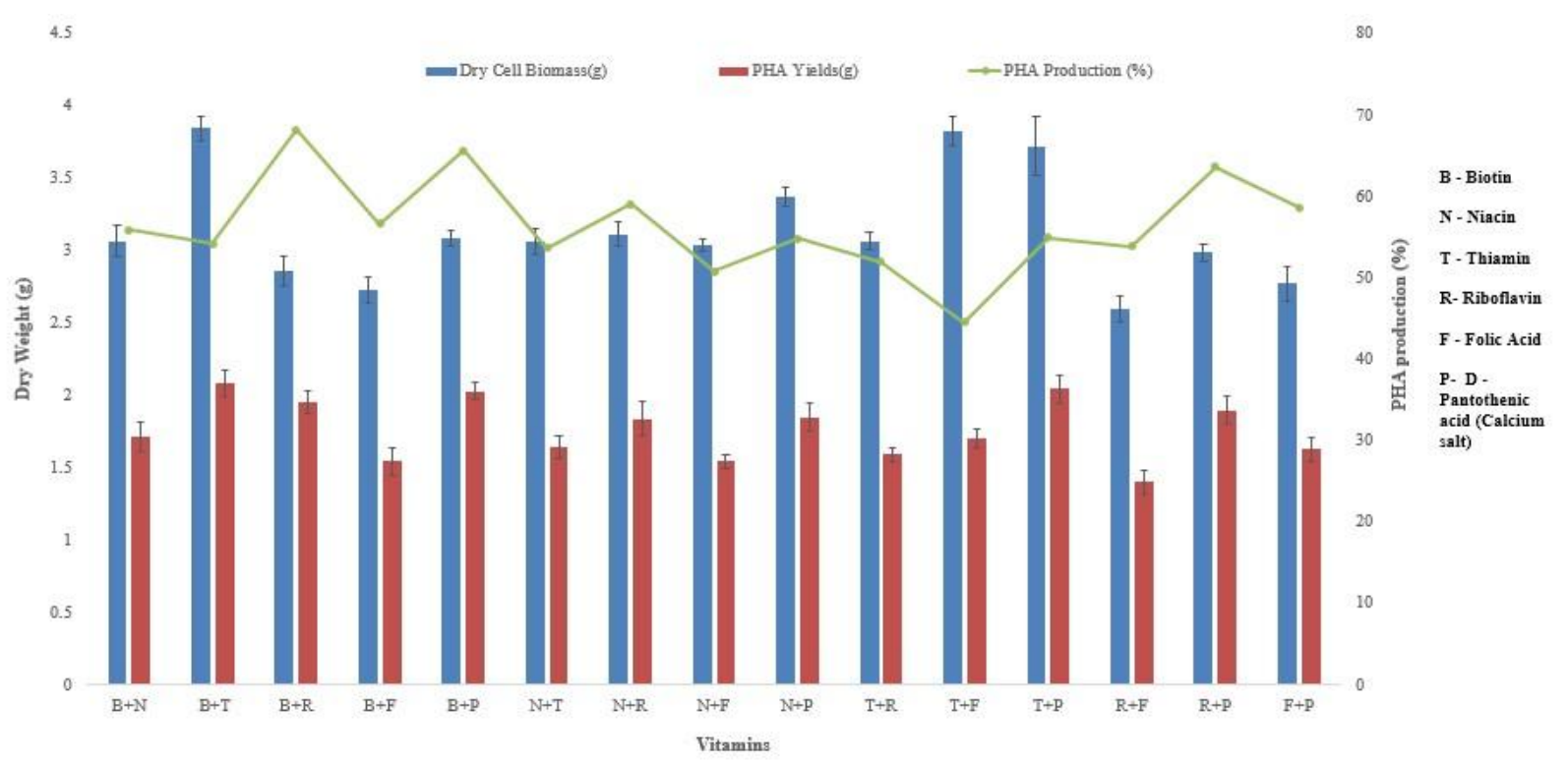


Fig.3 FTIR analysis of PHAs extracted from Zobellella sp.

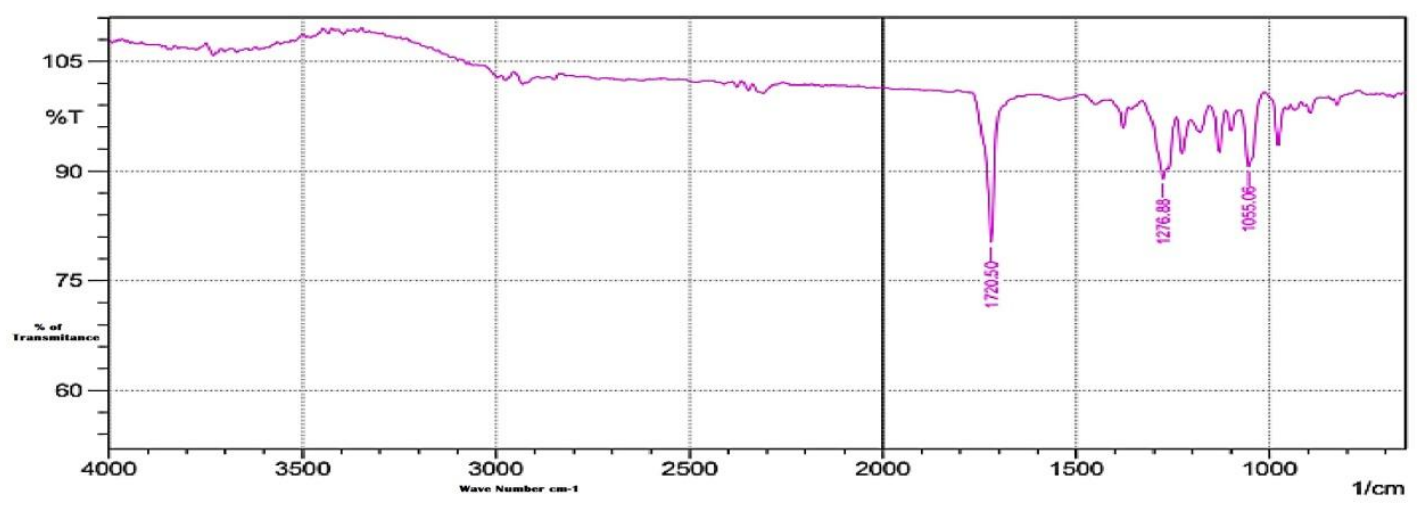

\section{FTIR spectral analysis of extracted PHAs}

The FTIR data indicated (Figure 3) different characteristic peak at $1055.06 \mathrm{~cm}^{-1}$ and $1276.88 \mathrm{~cm}^{-1}$ corresponding to $\mathrm{C}-\mathrm{N}$ stretch and $\mathrm{C}-\mathrm{C}, \mathrm{C}-\mathrm{H}, \mathrm{O}-\mathrm{H}$ stretch respectively. On the other hand, the high intense peak was obtained at $1720.50 \mathrm{~cm}^{-1}$ conferred to ester carbonyl $(\mathrm{C}=\mathrm{O})$ stretching vibration of PHB. Thus, IR spectrum depicts correct insight for the chemical configuration of $\mathrm{PHB}$, which is the most common homopolymer of PHAs. This result is also similar to the IR spectrum obtained at $1720.50 \mathrm{~cm}^{-1}$ corresponding to $(\mathrm{C}=\mathrm{O})$ ester carbonyl group, characteristics of PHB (Shah, 2012; Sharma and Bajaj, 2015).

The present study was designed to determine the effect of different vitamins on PHB production using high yielding bacterial isolates. As a result, Zobellella species showed the ability to accumulate $2.2 \mathrm{~g} / \mathrm{L}$ of PHB in growth medium with vitamins which can increases the cost of production. However, this finding will be paved the way of researchers during selection of suitable inexpensive carbon sources for PHB production. Raw materials (cane molasses, beet molasses, banana peel and fish waste) containing different vitamin such as biotin, folic acid, pantothenic acid, riboflavin, thiamine and niacin may be used for cost effective PHB production. Thus, extensive research is highly indispensible for bioconversion of vitamin containing raw materials for PHB production.

\section{Acknowledgement}

The authors are thankful to Dr. B. B. Mishra, HOD, Microbiology and staff of Central laboratory, OUAT for providing laboratory facilities during the period of study. The authors have no conflict of interest to declare.

\section{References}

Castilho, L.R., Mitchell, D.A. and Freire, D.M.G. 2009. Production of polyhydroxyalkanoates (PHAs) from waste materials and by-products by submerged and solid-state fermentation. Biores. Tech., 100: 5996-6009.

Chaudhry, W.N., Nazia, J., Ali, I., Ayaz, M.H. and Hasnain, S. 2010. Screening for polyhydroxyalkanoate (PHA)producing bacterial strains and comparison of PHA production from various inexpensive carbon sources. Ann. Microbiol., DOI 10.1007/s13213010-0181-6.

Chen, G.Q. 2009. A microbial 
polyhydroxyalkanoates (PHA) based bio- and materials industry. Chem. Soc.

Rev., 38: 2434-2446.

Das, Q., Chowdhury, J.U. and Anwar, M.N. 2005. Isolation, purification and characterization of biodegradable polymer producing bacteria Pseudomonas pseudomallei. Int. J. Agri. Biol., 7(1):114-117.

Dash, S., Mohapatra, S., Samantaray, D.P. and Sethi, A.K. 2014. Production of polyhydroxyalkanoates by sugar cane rhizospheric soil bacterial isolates. $J$. Pur. Appl. Microbiol., 8(6): 4889-4895.

Du, Q., Wang, H. and Xie, J. 2011. Thiamin (Vitamin B1) biosynthesis and regulation: a rich Source of antimicrobial drug targets?. Int. J. Biol. Sci., 7(1): 41-52.

Gomaa, E.Z. 2014. Production of polyhydroxyalkanoates (PHAs) by Bacillus subtilis and Escherichia coli grown on cane molasses fortified with ethanol. Braz. Arch. Biol. Technol., 57(1): 145-154.

Ibrahim, M.H.A. and Steinbuchel, A. 2009. Poly(3-Hydroxybutyrate) production from glycerol by Zobellella denitrificans MW1 via high-cell-density fed-batch fermentation and simplified solvent extraction. Appl. Environ. Microbiol., 75: 6222-6231.

Jin, J., Ring, L.C., Ken'ichiro, M. and Seiichi, T. 2009. Dual production of poly(3hydroxybutyrate) and glutamate using variable biotin concentrations in Corynebacterium glutamicum. J. Biosci. Bioeng., 107(4): 409-411.

Kalaivani, R. and Sukumaran, V. 2015. Enhancement of technique for optimized production of PHAs from marine bacteria, utilizing cheaply available carbon sources at Thanjavur district, India. Int. J. Curr. Microbiol. App. Sci., 4(4):408-417.

Khanna, S. and Srivastava, A.K. 2005.
Recent advances in microbial polyhydroxyalkanoates. Proc. Biochem., 40: 607-619.

Mohapatra, S. Samantaray, D.P., Samantaray, S.M., Mishra, B.B., Das, S., Majumdar, S., Pradhan, S.K., Rath, S.N., Rath, C.C., Akthar, J. and Achary, K.G. 2016. Structural and thermal characterization of PHAs produced by Lysinibacillus sp. through submerged fermentation process. Int. J. Biol. Macromol., 93:1161-1167.

Mohapatra, S., Mohanta, P.R., Sarkar, B., Daware, A., Kumar, C. and Samantaray, D.P. 2015. Production of polyhydroxyalkanoates (PHAs) by Bacillus strain isolated from waste water and its biochemical characterization. Proc. Natl. Acad. Sci., India, Sect. B. Biol., 1-8.

Mohapatra, S., Samantaray, D.P. and Samantaray, S.M. 2014. Phylogenetic heterogeneity of the rhizospheric soil bacterial isolates producing PHAs revealed by comparative analysis of 16s-rRNA. Int. J. Curr. Microbiol. appl. Sci., 3(5): 680-690.

Poli, A., Donato, P.D., Abbamondi, G.R. and Nicolaus, B. 2011. Synthesis, Production, and biotechnological applications of exo-polysaccharides and polyhydroxyalkanoates by archaea. Archaea, doi:10.1155/2011/693253.

Preciado1, A.G., Torres, A.G., Merino, E., Bonomi, H.R., Goldbaum, F.A. and Angulo, V.A. 2015. Extensive identification of bacterial riboflavin transporters and their distribution across bacterial species. Plos One, doi:10.1371/journal.pone.0126124.

Sangkharak, K. and Prasertsan, P. 2008. Nutrient optimization for production of polyhydroxybutyrate from halotolerant photosynthetic bacteria cultivated under aerobic-dark condition. Elec. J. Biotechnol., 11(3): 0717-3458. 
Shah, K.R. 2012. FTIR analysis of polyhydroxyalkanoates by novel Bacillus sp. AS 3-2 from soil of Kadi region, North Gujarat, India. J. Biochem. Tech., 3(4): 380-383.

Sharma, P. and Bajaj, B.K. 2015. Costeffective substrates for production of poly- $\beta$-hydroxybutyrate by a newly isolated Bacillus cereus PS-10. J. Env. Biol., 36:1297-1304.

Spiekerman, P., Rehm, B.H.A., Kalscheuer, R., Baumeister, D. and Steinbuchel, A. 1999. A semsitive, viable-colony staining method using nile red for direct screening of bacteria that accumulate polyhydroxy alkanoic acids and other lipid storage compounds. Arch. Microbiol., 17: 173-80.

Tortajada, M., Silva, L.F. and Prieto, M.A.
2013. Second-generation functionalized medium chain length polyhydroxyalkanoates: the gateway to high-value bioplastic applications. Int. J. Microbiol., 16: 1-15.

Varsha, Y.M. and Savitha, R. 2011. Overview on polyhydroxyalkanoates: a promising biopol. Microbial. Biochem. Technol., 3(5):099-105.

Waltz. 2008. Do biomaterials really mean business?. Nat. Biotech., 26: 851-853.

Xiao, N. and Jiao, N. 2011. Formation of polyhydroxyalkanoate in aerobic anoxygenic phototrophic bacteria and its relationship to carbon source and light availability. Appl. Environ. Microbial., 77: 7445-7450.

\section{How to cite this article:}

Maity, S., S. Das and Samantaray, D.P. 2017. Effect of Vitamin on Accumulation of PHB by Zobellella Species under Submerged Fermentation Process. Int.J.Curr.Microbiol.App.Sci. 6(2): 1310-1316. doi: http://dx.doi.org/10.20546/ijcmas.2017.602.148 